\title{
Evaluation of human enamel permeability exposed to bleaching agents
}

\author{
Diego Horning', Giovana Mongruel Gomes', Bruna Fortes Bittencourt', Lucas Manuel Ruiz', Alessandra Reis', \\ Osnara Maria Mongruel Gomes ${ }^{1}$
}

'Department of Restorative Dentistry, Dental School, State University of Ponta Grossa, Ponta Grossa, PR, Brazil

\begin{abstract}
Aim: To evaluate the human enamel permeability after different external bleaching techniques. Methods: The coronal portions of 20 maxillary human incisors were covered with an acid resistant varnish, except the labial surface, to prevent dye penetration of silver nitrate. The specimens were divided randomly into four groups $(n=5)$ according to the bleaching treatments: Group 1 (G1) - without bleaching agent (control group), Group 2 (G2) - 35\% hydrogen peroxide (HP) - one session of three 10-min applications, Group 3 (G3) - 35\% HP - 2 sessions of three 10-min applications, and Group 4 (G4) - 6\% HP - 14 days (1h/day). G1 was exposed to artificial saliva only and in the other groups the bleaching agents were applied following the manufacturers' recommendations. After bleaching, teeth were immersed in a 50\% silver nitrate solution for $2 \mathrm{~h}$ and photodeveloped for $16 \mathrm{~h}$. Then, three longitudinal slices of each tooth were photographed by an optical microscope (100x). The degree of dye penetration was analyzed in the middle third of the dental crowns using a 0 to 4 score system $(0=$ no dye penetration, $1=$ less than half the enamel thickness, $2=$ half of the enamel thickness, $3=$ full extent of enamel without reaching the dentin, and $4=$ tracer agent reaching dentin). The data were analyzed statistically by the KruskalWallis and Dunn tests $(\alpha=0.05)$. Results: The median ( $1^{\mathrm{st}} / 3^{\text {rd }}$ interquartiles) ranges were: $\mathrm{G} 1$ : 0(0/0), G2: 2(2/3), G3: 3(3/3) and G4: 3(3/3). G2, G3 and G4 showed significantly higher dye penetration compared with $\mathrm{G} 1(\mathrm{p}=0.0017)$. Conclusions: The use of bleaching agents increased dental enamel permeability, regardless of the bleaching technique.
\end{abstract}

Keywords: dental enamel, bleaching agents, permeability.

\section{Introduction}

Received for publication: March 21, 2013 Accepted: June 25, 2013

Correspondence to: Giovana Mongruel Gomes Rua Engenheiro Schamber 452, apto 21, CEP: 84010-340 - Ponta Grossa, PR, Brasil Phone: +55 4232226560 / Fax: +55 4232247351 E-mail: giomongruel@gmail.com
The current search for beauty and esthetic standards has increased the number of patients in dental offices drawn by tooth bleaching procedures ${ }^{1}$. This popularity increased the products availability to treat discolored teeth. The literature has several reports confirming that bleaching gels, on their various concentrations, are effective for tooth whitening ${ }^{2-3}$. Treatment modalities are basically two: athome and in-office techniques. At-home technique utilizes trays and lowconcentration bleaching gels, while in-office bleaching requires higher concentration gels, under professional supervision ${ }^{4}$.

It is well known that bleaching agents release oxygen in dental structures, which, due to its low molecular weight and associated to dental permeability, may diffuse through enamel and dentin substrates, acting on the pigments. These molecules, by means of redox reactions, can break macromolecules (pigments) into smaller molecular chains, which are totally or partially removed from dental structure by diffusion ${ }^{5}$. 
While some authors state that no significant chemical or morphological alterations may occur in the dental structure after bleaching procedures using different bleaching agents and concentrations ${ }^{5}$, other studies report that bleaching products may cause enamel mineral loss at different levels ${ }^{6}$ and alterations in surface morphology $y^{7-8}$. Theses alterations may vary depending on the product concentration, time of application $^{9-11}$ and $\mathrm{pH}$ of the product ${ }^{10-11}$.

Although several studies were conducted to evaluate the effects of dental bleaching on the tooth structure, divergent results are found in the literature, which requires further studies in order to investigate the safety of tooth bleaching in relation to teeth, as well as the effectiveness of the treatments ${ }^{12}$.

A model study was designed to assess penetration of bleaching agents through dental hard tissues using silver nitrate $^{13}$. This methodology can track the diffusion channels promoted by bleaching agents that may penetrate into enamel structure $^{14}$ and may be an indirect indicator of adverse effects of this treatment on the surface morphology of tooth structures ${ }^{12}$.

So far, the studies that evaluated the permeability of dental enamel to bleaching procedures were mainly conducted in bovine ename $1^{14}$. Although bovine teeth have been considered a good substitute for human teeth ${ }^{15}$, there are clear morphological differences between then, as human teeth are more susceptible to penetration of bleaching agent than bovine teeth ${ }^{16}$. Therefore the aim of this study was to compare the human enamel permeability after exposure to at-home and in-office bleaching agents.

\section{Material and methods}

The research project was approved by the Research Ethics Committee of the Dental School of the State University of Ponta Grossa, Report Number 50/2008 and Protocol Number $13033 / 08$. Twenty extracted human central incisors were stored in distilled water at $4^{\circ} \mathrm{C}$ and used within 6 months after extraction (ISO/TS $11405,2003{ }^{17}$ ). The teeth were scaled for the removal of periodontal tissue remnants and other debris, and then ultrasonically cleaned in distilled water (Dabi Atlante, Ribeirão Preto, SP, Brazil) in order to remove all organic and inorganic materials adhered to the coronal and root surfaces. All teeth were examined under 20x magnification (Zeiss, Estec, São Paulo, SP, Brazil) to detect enamel cracks, fractures, caries or other defects. In case such features were observed, the teeth were excluded from the sample.

The crowns of the selected teeth were separated from their roots at the cementoenamel junction (CEJ) using a lowspeed diamond saw (Isomet 1000, Buehler, Lake Bluff, IL, USA) under water cooling at $300 \mathrm{rpm}$. Then, the specimens were randomly divided into four groups $(\mathrm{n}=5)$ according to the bleaching treatments (Table 1). The labial surface of all specimens was subjected to the bleaching procedures, according to the experimental groups, following the manufacturers' instructions. The control group (G1) was exposed only to artificial saliva at $37^{\circ} \mathrm{C}$ in a dark environment and was not subjected to any bleaching treatment.

For G2 and G3, an in-office bleaching technique was used with 35\% hydrogen peroxide agent (PH35, Whiteness HP Maxx, FGM). Three drops of peroxide for 1 drop of thickener were mixed in a plate included in the bleaching kit. With the aid of a spatula, the labial surfaces were covered with a gel layer $1 \mathrm{~mm}$ thick. Then, the bleaching agent was light activated for $3 \mathrm{~min}$ (Whitening Laser II, DMC, São Carlos, SP, Brazil) and 7 min without light exposure. This procedure was repeated 3 times, with no waiting time between the applications. The gel was removed with a cotton pellet. For G3, another session was performed, repeating the same procedures, totalizing 2 sessions of three 10-min applications, with a 7-day interval. During this period the specimens were stored in artificial saliva at $37^{\circ} \mathrm{C}$ in a dark environment.

For G4, an at-home bleaching protocol was used with $6 \%$ hydrogen peroxide agent (White Class Calcium, FGM). The gel was applied for 14 consecutive days, $1 \mathrm{~h}$ per day. In the remaining period, the specimens were also stored in artificial saliva at $37^{\circ} \mathrm{C}$ in a dark environment during the treatment period.

Table 1 - Experimental groups, bleaching agents, composition and application procedure used in this study.

\begin{tabular}{lcc}
\hline $\begin{array}{l}\text { Groups } \\
(n=5)\end{array}$ & Bleaching agent/ Composition/ pH & Application procedure \\
$\mathrm{G} 1$ & - & Without bleaching agent (Control group)
\end{tabular}

G2 Whiteness HP Maxx (FGM Dental Products, Joinville, SC, Brazil)35\% Hydrogen Peroxide (PH35), thickening agent, colorant, glycol, inorganic filler and deionized water $\mathrm{pH} \sim 5.5$ one session of three 10-min applications

Whiteness HP Maxx (FGM Dental Products, Joinville, SC, Brazil)35\% Hydrogen Peroxide (PH35), thickening agent, colorant, glycol, inorganic filler and deionized water $\mathrm{pH} \sim 5.5$ 
After the end of the bleaching procedures, all specimens were stored in artificial saliva for $48 \mathrm{~h}$, in a dark environment at $37^{\circ} \mathrm{C}$. After this period, the specimens were ultrasonically cleaned once again for $5 \mathrm{~min}$, in order to remove any other debris from the enamel external surfaces.

After these procedures, the specimens were dried at room temperature for $12 \mathrm{~h}$ and the lingual, proximal surfaces and the CEJ were sealed with cyanoacrylate resin (Super bonder Loctite, Henkel Ltda, São Paulo, SP, Brazil) and a nail varnish (Rebu, Risqué Niasi, Taboão da Serra, SP, Brazil) to prevent dye penetration of silver nitrate (tracer agent) through this area. The nail varnish was also used to delimitate an area of $4 \times 4 \mathrm{~mm}$ in the middle third of the labial surface. Specimens were then immersed in $50 \%$ aqueous silver nitrate solution (Vetec Química Fina, Xerém, RJ, Brazil) for 2 h, in a dark and closed environment. Subsequently, the specimens were photodeveloped for $16 \mathrm{~h}$ (Developing solution, Kodak, Eastman Kodak Company, Rochester, NY, USA). After this period, the specimens were cleaned with tap water and the nail varnish layer was removed with manual cutting instruments.

The specimens were then embedded in a polyvinyl chloride (PVC) tube with acrylic resin (Duralay, Reliance, Dental Mfg. Co., Worth, IL, USA), and three longitudinal slices of each tooth with approximately $0.4 \mathrm{~mm}$ thick were obtained in a buccolingual direction, with a low-speed diamond saw (Isomet 1000, Buehler, Lake Bluff, IL, USA), under water cooling.

The slices were then photographed under an optical microscope (Leica ${ }^{\circledR}$, Olympus BX41-U-CA, Tokyo, Japan) with 100x magnification. The images were taken with a digital camera, resolution of 5.1 megapixels. The dye penetration degree was analyzed by three previously calibrated evaluators, using a 0 to 4 score system: score $0=$ no dye penetration; score $1=$ less than half the enamel thickness; score 2 = half of the enamel thickness; score 3 = full extent of enamel without reaching the dentin and score $4=$ tracer agent reaching dentin. A flow-chart of the different scores of the dye penetration degree may be seen in Figure 1. This evaluation was determined by visualizing the middle third of the dental crowns. If there was any disagreement between the evaluators, the sample under discussion was analyzed jointly until a consensus was reached. The median scores of the images from the same tooth were considered for statistical analysis using the Kruskal Wallis and Dunn tests $(\alpha=0.05)$.

\section{Results}

The medians and interquartile ranges for the permeability degree obtained from each group are shown in Table 2. The statistical analysis revealed a significant effect for the
Table 2 - Medians ( $1^{\text {st }} / 3^{\text {rd }}$ interquartiles) for permeability degree and significance of all experimental groups.

\begin{tabular}{lcc}
\hline Groups & Medians(1st/ $3^{\text {rd }}$ interquartiles) & Significance * \\
G1 & $0(0 / 0)$ & $\mathrm{A}$ \\
G2 & $2(2 / 3)$ & $B$ \\
G3 & $3(3 / 3)$ & $B$ \\
G4 & $3(3 / 3)$ & $B$
\end{tabular}

${ }^{*}$ Different letters indicate statistically significant differences $(p \leq 0.05)$.

evaluated factor $(p=0.0017)$. No significant differences were observed between the bleached groups (G2, G3 and G4) but all these groups showed significantly higher permeability compared to control group (G1). In Figure 2, one can observe that there was no dye penetration in G1, and in G2, G3 and G4 the tracer agent penetrated just on enamel, without reach dentin.

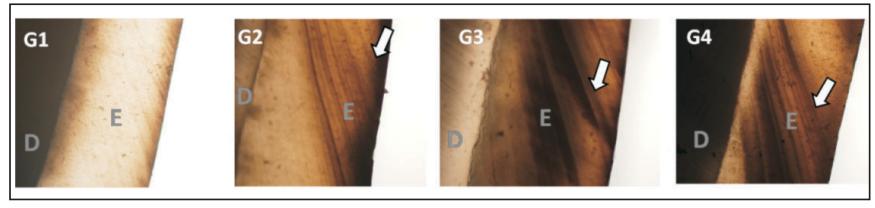

Fig. 2 - Stereomicroscopic image (100 X magnification) of the permeability degree obtained from each group. It may be visualized that there was no dye penetration in G1, and in G2, G3 and G4 the tracer agent (arrow) penetrated only on enamel, without reaching dentin. $\mathrm{E}$ - enamel; D - dentin.

\section{Discussion}

There are currently three techniques for bleaching purposes: in-office bleaching, at-home bleaching and overthe-counter products ${ }^{3}$. This study verified the influence of the in-office and at-home approaches on enamel permeability by silver nitrate penetration. The results showed no differences between the bleaching protocols.

A FT-IR spectroscopy study found that enamel alterations after in-office and at-home bleaching are dependent on the concentration and treatment time, since treatments for longer periods and at higher concentrations resulted in higher structural alterations in enamel ${ }^{9}$. However, in the present study, there were no significant differences between the bleached groups, regardless the used bleaching agent and the bleaching protocol.

Lower enamel permeability could be expected with the at-home product. However, an earlier study found no significant differences between 1, 7 or 14 applications (days) of a $10 \%$ carbamide peroxide agent ${ }^{18}$. Additionally, although the at-home bleaching agent has a lower hydrogen peroxide concentration, the product was used for 14 days and the effects on enamel permeability were only evaluated at the end of this 14-day period. Thus, the low concentration gel
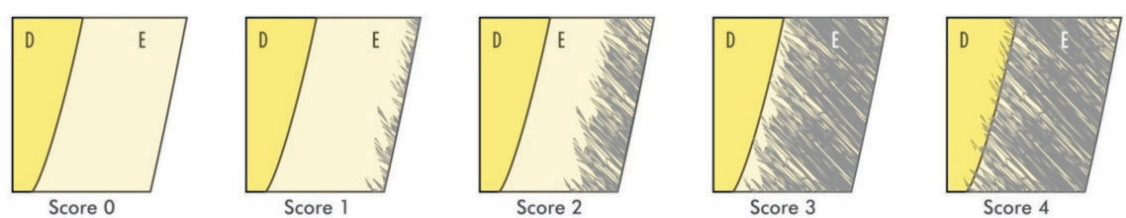

Fig. 1 - Flowchart of the different scores for the dye penetration degree. E - enamel; D - dentin. 
was applied for a longer period than the in-office gel, which may explain the similar results obtained.

Furthermore, there are studies reporting that the $\mathrm{pH}$ values of the bleaching agents have a direct influence on the chemical and morphological structure of bleached enamel. Neutral bleaching agents (30\% hydrogen peroxide) caused minor deleterious effects on enamel compared to an acidic bleaching agent (also hydrogen peroxide) at the same concentration of $30 \%{ }^{10}$. Usually, at-home bleaching agents have lower $\mathrm{pH}$ than in-office systems ${ }^{19}$ and this may also interfere with the enamel permeability. In the present investigation, care was taken to select at-home and bleaching system with similar $\mathrm{pH}$ (Whiteness HP Maxx $\mathrm{pH} \sim 5.5$; White Class $6 \% \mathrm{pH} \sim 6.2$ ) in order to minimize the effects of $\mathrm{pH}$ on enamel permeability ${ }^{19}$.

In the present research, all bleached groups showed a higher permeability compared to the control group. Likewise, Mendonça et al. ${ }^{14}$ reported a higher degree of silver nitrate penetration in bleached enamel specimens, explaining that bleaching procedure opens diffusion channels in the tooth structure through which the oxygen molecules are carried into the dentin substrate. Additionally, the superficial alterations occurred in enamel structure, observed by SEM $^{14}$, and it may be speculated that subsurface damages also occurred in that tissue. In contrast, another study revealed, also by SEM observations, that despite some morphological alterations that may occur, bleaching may be considered safe for enamel, as a regional variation of the dental substrate may amplify the effects of 35\% hydrogen peroxide and $10 \%$ carbamide peroxide ${ }^{20}$.

The methodology employed in this study was first reported by Iwamoto et al. ${ }^{13}$ who observed silver nitrate penetration through dental structures subjected to bleaching therapy. However, different from the findings of this study, those authors found no penetration of the agent through the tooth structure. Perhaps this fact may be attributed to a shorter exposure period of the specimens to silver nitrate, which was only $1 \mathrm{~h}$. In the present investigation a 2-hour immersion period was used, which agrees with earlier studies ${ }^{14}$.

The adverse effects caused by bleaching procedures on dental structures have been extensively studied. Researches demonstrated several alterations on dental hard structures, as increased surface roughness ${ }^{7-8}$, reduction in microhardness values $^{6}$ and pulpal responses ${ }^{21}$, as showed in a previous study that found direct damage to odontoblasts and decreased metabolic activity of these cells ${ }^{22}$. This effect may be due to the fact that low molecular weight reactive oxygen is more likely to penetrate dental structure than the silver nitrate used in this study. These findings suggest the need to supervise the use of bleaching agents, since oxygen molecules released by decomposition of these agents may reach the pulp chamber ${ }^{16}$ and cause toxic effects to pulp cells ${ }^{23-24}$.

Some in vitro studies use remineralizing solutions to store the specimens, such as HBSS (Hank's saline solution), basically formed by salts ${ }^{25}$. Another alternative is the use of artificial saliva, like in the present study, because it simulates accurately intraoral conditions ${ }^{26}$, compared to storage in distilled water. Also, due to its high mineral content, artificial saliva $^{27}$ or natural human saliva ${ }^{11}$ may increase remineralization of bleached enamel, different from distilled water, which has no remineralizing effect.

Since this is an in vitro study, clinical extrapolations are limited. Vongsavan and Matthews ${ }^{28}$ reported that the results obtained from in vitro studies do not correspond to in vivo reality. The authors state that in the oral cavity, there is a fluid movement within the dentinal tubules and enamel porosities. This may render the penetration of bleaching agents under in vivo conditions but not under in vitro conditions ${ }^{29}$. Considering all the above-mentioned physiological factors that may affect the results, more clinical studies should be performed, in order to determine the actual effect of bleaching agents on enamel.

\section{References}

1. Tin-Oo MM, Saddki N, Hassan N. Factors influencing patient satisfaction with dental appearance and treatments they desire to improve aesthetics. BMC Oral Health. 2011; 11: 6

2. Haywood VB, Heymann HO. Nightguard vital bleaching. Quintessence Int. 1989; 20: 173-6.

3. Heymann HO. Tooth whitening: facts and fallacies. Brit Dent J. 2005; 198: 514.

4. LiY. Safety controversies in tooth bleaching. Dent Clin NAm. 2011; 55: 255-63.

5. Haywood VB, Hook V, Heymann H. Nightguard vital bleaching effects of various solutions on enamel surface texture and color. Quintessence Int. 1991; 22: 775-82.

6. Al-Salehi SK, Wood DJ, Hatton PV. The effect of $24 \mathrm{~h}$ non-stop hydrogen peroxide concentration on bovine enamel and dentin mineral content and microhardness. J Dent. 2007; 35: 845-50.

7. Cavalli V, Arrais CAG, Giannini M. Influence of low-concentrated bleaching agents on the human enamel roughness and morphology. ClipeOdontoUNITAU. 2009; 1: 14-9.

8. Martin JM, De Almeida JB, Rosa EA, Soares P, Torno V, Rached RN, et al. Effects of fluoride therapies on the surface roughness of human enamel exposed to bleaching agents. Quintessence Int. 2010; 41:71-8.

9. Bistey T, Nagy IP, Simó A, Hegedus C. In vitro FT-IR study of the effects of hydrogen peroxide on superficial tooth enamel. J Dent. 2007; 35: 325-30.

10. Sun L, Liang S, Sa Y, Wang Z, Ma X, Jiang T, et al. Surface alteration of human tooth enamel subjected to acidic and neutral $30 \%$ hydrogen peroxide. J Dent. 2011; 39: 686-92.

11. Sa Y, Chen D, Liu Y, Wen W, Xu M, Jiang T, et al. Effects of two in-office bleaching agents with different $\mathrm{pH}$ values on enamel surface structure and colour: an in situ vs. in vitro study. J Dent. 2012; 40: e26-34.

12. Minoux M, Serfaty R. Vital tooth bleaching: biologic adverse effects - a review. Quintessence Int. 2008; 39: 645-59.

13. Iwamoto $\mathrm{N}$, Shimada Y, Tagami J. Penetration of silver nitrate into bleached enamel, dentin, and cementum. Quintessence Int. 2007; 38: e183-8.

14. Mendonça LC, Naves LZ, Garcia LFR, Correr-Sobrinho L, Soares CJ, Quagliatto PS. Permeability, roughness and topography of enamel after bleaching: tracking channels of penetration with silver nitrate. Braz J Oral Sci. 2011; 10: 1-6.

15. Krifka S, Börzsönyi A, Koch A, Hiller KA, Schmalz G, Friedl KH. Bond strength of adhesive systems to dentin and enamel-human vs. bovine primary teeth in vitro. Dent Mater. 2008; 24: 888-94.

16. Camargo SEA, Valera MC, Camargo CHR, Mancini MNG, Menezes MM. Penetration of $38 \%$ hydrogen peroxide into the pulp chamber in bovine and human teeth submitted to office bleach technique. J Endod. 2007; 33: 1074-7. 
17. International Standardization for Organization. Guidance on testing of adhesion to tooth structure. Geneve, Switzerland; 2003. CD TR 11405.

18. Soares DGS, Ribeiro APD, Sacono NT, Coldebella CR, Hebling J, Souza Costa CA. Transenamel and transdentinal cytotoxicity of carbamide peroxide bleaching gels on odontoblast-like MDPC-23 cells. Int Endod J. 2011; 44: 116-25.

19. Freire A, Archegas LR, de Souza EM, Vieira S. Effect of storage temperature on $\mathrm{pH}$ of in-office and at-home dental bleaching agents. Acta Odontol Latinoam. 2009; 22: 27-31.

20. Spalding M, Taveira LA, De Assis GF. Scanning electron microscopy study of dental enamel surface exposed to $35 \%$ hydrogen peroxide: alone, with saliva, and with $10 \%$ carbamide peroxide. J Esthet Restor Dent. 2003; 15: 154-64.

21. de Oliveira MAVC, Quagliatto PS, Magalhães D, Biffi JCG. Effects of bleaching agents and adhesive systems in dental pulp: a literature review. Braz J Oral Sci. 2012; 11: 428-32.

22. Dias Ribeiro AP, Sacono NT, Lessa FCR, Nogueira I, Coldebella CR, Hebling J, et al. Cytotoxic effect of a 35\% hydrogen peroxide bleaching gel on odontoblast-like MDPC-23 cells. Oral Surg Oral Med Oral Pathol Oral Radiol Endod. 2009; 108: 458-64.

23. Coldebella CR, Ribeiro APD, Sacono NT, Trindade FZ, Hebling J, Costa CAS. Indirect cytotoxicity of a $35 \%$ hydrogen peroxide bleaching gel on cultured odontoblast-like cells. Braz Dent J. 2009; 20: 267-74.

24. Dantas CMG, Vivan CL, Ferreira LS, Freitas PM, Marques MM. In vitro effect of low intensity laser on the cytotoxicity produced by substances released by bleaching gel. Braz Oral Res. 2010; 24: 460-6.

25. Chuang SF, Chen HP, Chang CH, Liu JK. Effect of fluoridated carbamide peroxide gels on enamel microtensile bond strength. Eur J Oral Sci. 2009; 117: 435-41.

26. Uysal T, Basciftci FA, Usumez S, Sari Z, Buyukerkmen A. Can previously bleached teeth be bonded safely? Am J Orthod Dentofacial Orthop. 2003; 123: 628-32.

27. Cavalli V, Reis AF, Giannini M, Ambrosano GM. The effect of elapsed times following bleaching on enamel bond strength of resin composite. Oper Dent. 2001; 26: 597-602.

28. Vongsavan $\mathrm{N}$, Matthews $\mathrm{B}$. The permeability of cat dentin in vivo and in vitro. Arch Oral Biol. 1991; 36: 641-6.

29. Berger SB, Pavan S, Dos Santos PH, Giannini M, Bedran-Russo AK. Effect of bleaching on sound enamel and with early artificial caries lesions using confocal laser microscopy. Braz Dent J. 2012; 23: 110-5. 